\title{
Qualidade do melão exportado pelo porto de Natal-RN
}

\author{
Quality of melon exported through the port of Natal Rio Grande do Norte State, Brazil
}

\author{
Rui Sales Júnior ${ }^{1 *}$ Flavio Fernandes Dantas² \\ Alessandra Monteiro Salviano ${ }^{3}$ \\ Glauber Henrique Souza Nunes ${ }^{1}$
}

\begin{abstract}
Com o objetivo de avaliar a qualidade pós-colheita dos melóes exportados pelo Porto de Natal-RN, identificando características qualitativas desfavoráveis que dificultem a exportação do melão, foram analisados 2.303 frutos no período de setembro a dezembro de 2002 com amostragem segundo as normas de fiscalização da Delegacia da Agricultura e do Abastecimento- DFA/SSV. O trabalho foi desenvolvido no Porto de Natal, na unidade do Vigiagro/SSV/MA. A avaliação dos frutos foi feita de maneira sistemática, seguindo o preenchimento de uma "Ficha de Controle de Qualidade do Melão Exportado" em que foram determinados o teor de sólidos solúveis totais e a firmeza de polpa. 50,33\% dos frutos analisados foram do tipo Amarelo, 19,06 \% do tipo Orange Flesh, 9,90\% do tipo Pele de Sapo, 11,16\% do tipo Gália, 7,03 \% do tipo Cantaloupe e 2,52\% do tipo Charentais. Apenas os melóes tipo Amarelo apresentaram teor médio de sólidos solúveis totais aceitáveis para a exportação; os melões tipo Pele de Sapo foram os que apresentaram menos firmeza de polpa.
\end{abstract}

Palavras-chave: Cucumis melo, sólidos solúveis totais, firmeza de polpa.

\section{ABSTRACT}

Brazil was studied. The post quality harvest from the melon exported from the Natal-RN port, the qualitative characteristics unfavorable to the market 2,303 fruits were analyzed from September to December of 2002 .Sampling was done according to control norms of Delegacia da Agricultura e do Abastecimento - DFA/SSV. The work was developed in the
Natal port, on unit of Vigiagro/SSV/MA. The study in systematic form, using a special form "Card of Quality Control of the Melon Exported" was determined. The contents of solid solubles and pulp firmness. The yellow type were $50.33 \%$ from the fruits of the total, $19.06 \%$ of the Orange Flesh, $9.90 \%$ of the Piel de Sapo, $11.60 \%$ of the Gália, $7.03 \%$ of the Cantaloupe and $2.52 \%$ of the Charentais type. Only the melon Yellow type presented content average of solids soluble accepted for export. The Piel de Sapo melons presented the less firmness of pulp.

Key words: Cucumis melo, solid soluble, firmness pulp.

O estado do Rio Grande do Norte é considerado o maior produtor e exportador de melão (Cucumis melo L.) do Brasil. Segundo dados do Secex/ DTIC (2002), foram exportadas pelo Porto de Natal-RN, aproximadamente 98 mil toneladas de melões, gerando uma renda free on board (FOB) ao redor de US\$ 37,8 milhões de dólares, superando os valores das exportações de 2001 em aproximadamente $28 \%$ (SALES JÚNIOR et al., 2004). Entre os principais tipos de melões produzidos na região, destaca-se o Pele de Sapo, o Gália, o Cantaloupe, o Charentais, o Amarelo e o Orange Flesh.

Considerando a tendência mundial de incrementar as barreiras não tarifárias como meio de proteger a produção interna, os produtores e exportadores brasileiros necessitam manter-se atualizados com relação às mudanças das exigências

${ }^{1}$ Departamento de Ciências Vegetais da Escola Superior de Agricultura de Mossoró (ESAM), CP 137, 59625-900, Mossoró, RN, Brasil. E-mail: ruisales@esam.br. *Autor de correspondência.

${ }^{2}$ Universidade Potiguar, Natal, RN, Brasil.

${ }^{3}$ Embrapa Semi-Árido, CP 23, 56302-970, Petrolina, PE. E-mail: amendes@ cpatsa.embrapa.br 
de mercado, para desenvolverem, com órgãos governamentais, ações com objetivo de reduzir seus impactos nas exportações buscando oferecer frutos com maior qualidade ao mercado.

Entre as principais variáveis qualitativas estudadas em pós-colheita de frutos, merecem destaque, a firmeza de polpa, que afeta a resistência ao transporte, assim como a vida útil (MENEZES et al., 1998), e o teor de sólidos solúveis totais (SST), tradicionalmente utilizado para expressar a qualidade (PROTRADE, 1995). As características relacionadas com a qualidade dos frutos são diretamente afetadas pelas condições de cultivo. O teor de SST aumenta quando se aumenta a salinidade no solo e, em compensação, diminui quando se aumenta a densidade de plantio (MENDLINGER, 1994). Outro fator importante é o momento da colheita, pois a concentração de SST dos melões comercializáveis não deve ser menor do que $10^{\circ}$ Brix (VALLESPIR, 1999). Analisando as exigências do mercado, SOUZA et al. (1994) verificaram que os melões cultivados para exportação devem ser colhidos com um teor de SST variando de 9 a $11^{\circ}$ Brix enquanto que, para o mercado interno, devem possuir um teor de 12 a $14^{\circ}$ Brix.

Este trabalho teve como objetivo avaliar a qualidade dos melões exportados pelo Porto de Natal$\mathrm{RN}$.

No período de 05 de setembro a 07 de dezembro de 2002, foram coletados e analisados 2.303 melões provenientes de paletes de 25 empresas produtoras. As amostragens foram efetuadas semanalmente, sendo retiradas duas caixas por tipo de melão/empresa/embarque, escolhidas aleatoriamente dos paletes, representando assim, 0,02\% das caixas exportadas.

O procedimento de amostragem está conforme as Normas do Laboratório de Vigilância Agropecuária da DFA/RN (VIGIAGRO)-MAPA. Duas avaliações foram realizadas nos frutos - firmeza de polpa (FP) e o teor de sólidos solúveis totais (SST). A medida de FP foi feita por meio de um penetrômetro com sonda de ponta cônica de $8 \mathrm{~mm}$ de diâmetro, e os resultados obtidos em libras, convertidos para Newton (N), multiplicando-o pelo fator de conversão 4,45 (GOMES JUNIOR et al., 2001). Em cada fruto, foi realizado um corte longitudinal, no qual foram efetuadas duas leituras eqüidistantes em cada uma das metades equatoriais do fruto. O teor de SST foi obtido mediante um refratômetro óptico ATAGO N-1E (0-32\%) no qual se efetuaram as leituras do suco obtido de cada fruto.

Os dados foram submetidos à análise de variância (amostra aleatória estratificada, na qual cada empresa corresponde a um extrato) para detectar diferenças entre e dentro das empresas ao nível de $1 \%$ de probabilidade.

O melão tipo Amarelo representou, no período estudado, 50,33 \% das exportações. O melão tipo Orange Flesh representou aproximadamente 19,06\% das exportações e o tipo Pele de Sapo 9,90\%. Os demais tipos - Galia, Cantaloupe e Charentais considerados nobres pelos produtores, representaram apenas $11,16 \% ; 7,03 \%$ e $2,52 \%$, respectivamente. Comparando aos dados encontrados, no mesmo período do ano anterior, SALES JÚNIOR et al. (2004) verificaram uma queda na quantidade do melão tipo amarelo exportado pelo Porto de Natal em detrimento dos tipos Orange Flesh, Gália e Cantaloupe. No caso do melão tipo Gália, o volume exportado em 2002 dobrou em relação ao mesmo período do ano anterior $-5,77 \%$ (SALES JÚNIOR et al., 2004). Essa mudança é explicada pela exigência exigência do mercado consumidor por melões com teores mais elevados de sólidos solúveis totais. Não obstante, mesmo sabendo que esses tipos de melões apresentam um valor mais alto no mercado internacional, é importante ressaltar que requerem um manejo pós-colheita diferenciado, já que o processo de maturação dos frutos continua mesmo depois de colhido, o que exige um processamento rápido e uma cadeia de frio eficiente para manter as suas qualidades organolépticas (GIAMBANCO DE ENA,1997a; b). Segundo estudo realizado por SOARES (2001), em 2001, apenas seis empresas do estado do RN produziam e exportavam melão tipo Gália. Os resultados deste estudo mostram que, em 2002, esse número passou para 10. Para os demais tipos de melões, não se verificou um aumento no $\mathrm{n}^{\circ}$ de empresas exportadoras.

A análise de variância detectou diferença estatística significativa ao nível de $1 \%$ de probabilidade, entre as empresas amostradas, quanto à firmeza de polpa para todos tipos de melão analisados, exceto o tipo cantaloupe. O melão tipo Orange Flesh apresentou o maior percentual de frutos com FP superior ao mínimo exigido (73,80\%), seguido por melões tipo Amarelo $(52,02 \%)$, Gália $(46,5 \%)$, Charentais $(41,38 \%)$ e Cantaloupe $(33,15 \%)$, sendo os valores mínimos exigidos de 30, 24, 30 e $35 \mathrm{~N}$, respectivamente. O melão tipo Pele de Sapo foi o que apresentou o maior percentual de frutos com FP inferior ao mínimo exigido (95,52\%), que segundo ALVES et al. (2000) é de 32N (Figura 1). Em comparação com as exportações de 2001 (SALES JÚNIOR et al. 2004), percebeu-se um aumento na quantidade de frutos com FP abaixo do mínimo exigido, com diferenças de $25,52 \%$ a $32,98 \%$, para os tipos Pele de Sapo e Amarelo, respectivamente.

Observou-se diferença significativa ao nível de $1 \%$ de probabilidade, entre as empresas, para o teor 


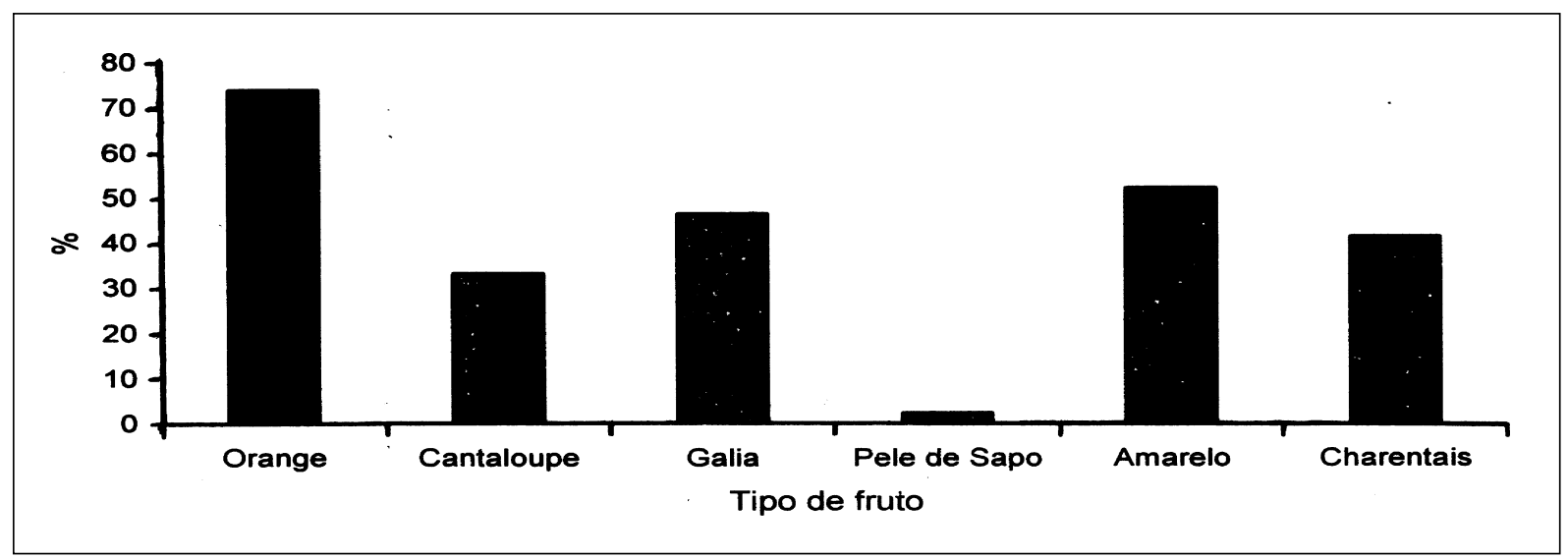

Figura 1 - Porcentagem dos melões exportados pelo Porto de Natal-RN, no período de 05 de setembro a 07 de dezembro de 2002 , que apresentavam firmeza de polpa superior à mínima exigida para exportação. Mossoró, ESAM (2002).

de SST apenas para os melões dos tipos Amarelo, Charentais, Orange Flesh e Pele de Sapo, sendo o melão tipo Amarelo o que apresentou maior percentual de frutos $(71,85 \%)$, com teores de SST acima do mínimo exigido, de $10^{\circ}$ Brix. Ao contrario, o melão tipo Charentais apresentou 91,58\% dos frutos analisados com valor de SST inferior ao mínimo aceitável pelo mercado internacional, de $13^{\circ}$ Brix (ALVES et al., 2000). Os demais tipos, Gália, Pele de Sapo, Cantaloupe e Orange Flesh apresentaram valores médios de SST, 87,86\%; 58,92\%; $35,57 \%$ e $41,02 \%$, respectivamente, inferiores aos mínimos exigido pelo mercado internacional, de 12, 11, 10 e $10^{\circ}$ Brix, respectivamente, segundo ALVES et al. 2000 (Figura 2). Comparando os dados de qualidade encontrados por SALES JÚNIOR et al. (2004), no mesmo período de 2001, aprecia-se uma melhoria na qualidade dos frutos exportados pela redução da porcentagem de frutos com teor de SST abaixo dos mínimos exigidos pelo mercado internacional, que variou de $27,00 \%$ a $8,32 \%$, principalmente para os tipos Charentais e Amarelo. A exceção foi o melão tipo Gália, que aumentou em $6,51 \%$ o número de frutos abaixo do mínimo de SST exigido pelo mercado internacional. Os menores valores obtidos em 2001 por SALES JÚNIOR et al. (2004), provavelmente, foram influenciados pela ocorrência de uma epidemia viral, "amarelão do meloeiro" de etiologia ainda não esclarecida (LIMA et al., 2002; NAGATA et al., 2005) transmitida pela mosca branca (Bemisia tabaci) e que interfere na translocação de açúcares para o fruto (SILVA et al., 2002).

Alguns autores divergem com relação aos teores adequados de SST para diferentes tipos de

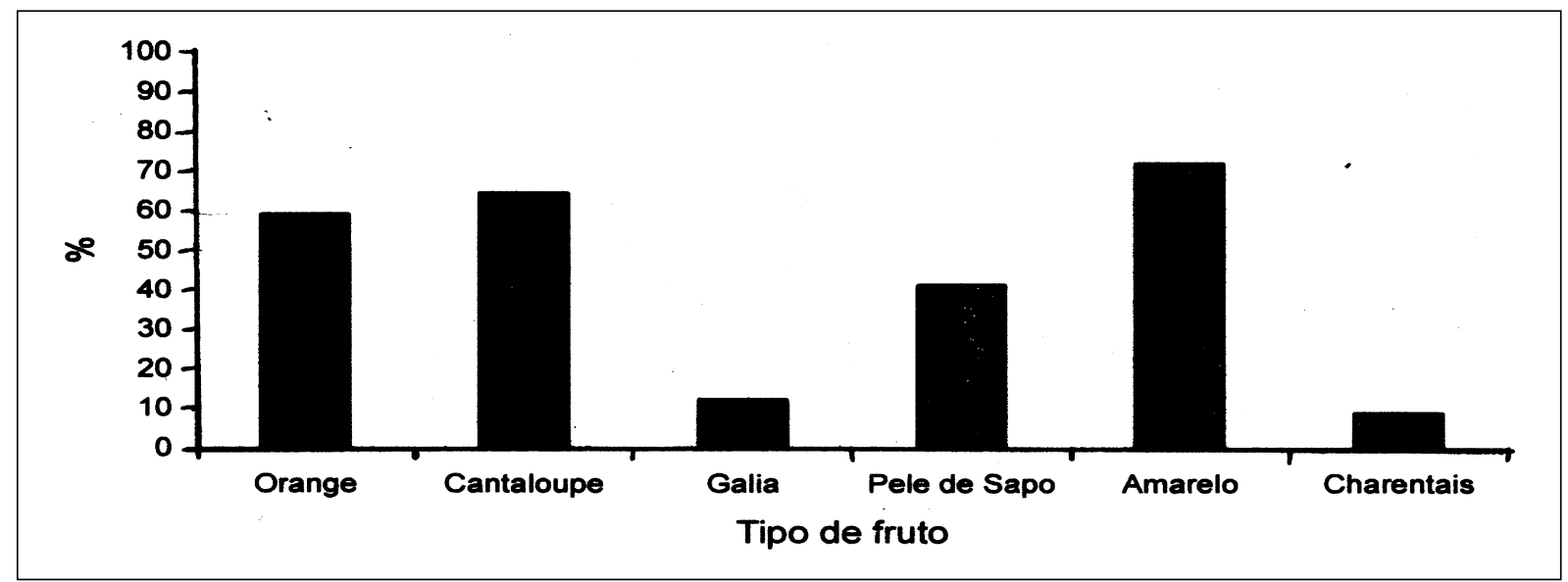

Figura 2 - Porcentagem dos melões exportados pelo Porto de Natal-RN, no período de 05 de setembro a 07 de dezembro de 2002, que apresentavam teor de Sólidos Solúveis Totais (SST) superior ao mínimo exigido para exportação. Mossoró, ESAM (2002).

Ciência Rural, v.36, n.1, jan-fev, 2006. 
melões. GIAMBANCODEENA (1997a) recomenda teor de SST entre 12 e $14^{\circ}$ Brix para os melões tipo Amarelo e Gália, sendo o teor de SST para o melão tipo Amarelo superior ao recomendado por ALVES et al. (2000). É possível que os teores atribuídos por GIAMBANCO DEENA (1997a) sejam os exigidos para o mercado interno espanhol ou para mercado de curtas distâncias. Esse autor ainda recomenda para os melões tipo Pele de Sapo e Cantaloupe teor de SST superior a 12 e 10, respectivamente, podendo oscilar de 13 a $15^{\circ}$ Brix, no caso do tipo Charentais. Foi detectada uma pequena melhora de qualidade no teor de SST nos frutos de melão exportados em 2002 quando comparado ao ano de 2001. Sendo assim, diante das exigências de qualidade de frutos impostas pelos mercados importadores, é de suma importância que os produtores do Pólo Fruticultor Assu-Mossoró busquem aperfeiçoamento das técnicas de manejo da cultura, de modo a elevar o padrão de qualidade dos frutos produzidos como forma de garantir a sua permanência no mercado externo.

\section{REFERÊNCIAS}

ALVES, R.E. et al. Manual de melão para exportação. Brasília: EMBRAPA, 2000. 51p.

GOMES JÚNIOR, J. et al. Qualidade pós-colheita do melão tipo Cantaloupe, colhido em dois estádios de maturação. Horticultura Brasileira, v.19, n.3, p.356-360, 2001.

GIAMBANCO DE ENA, H. Manejo poscosecha del melón. In: NAMESNY, A.R. Melones. Barcelona: Ediciones de Horticultura, 1997a. p.165-174.

GIAMBANCO DE ENA, H. Comercialización del melón. In: NAMESNY, A.R. Melones. Barcelona: Ediciones de Horticultura, 1997b. p.175-178.
LIMA, J.A.A. et al. Estudos preliminares do vírus do amarelão do meloeiro. In: CONGRESSO BRASILEIRO DE FItopatologia, 35., 2002, Recife, PE. Palestras e Resumos... Brasília-DF: Sociedade Brasileira de Fitopatologia - SBF, 2002. V.27 (Suplemento). p.S207.

MENDLINGER, S. Effect of increasing plant density and salinity on yield and fruit quality in muskmelon. Scientia Horticulturae, v.57, p.41-49, 1994

MENEZES, J.B. et al. Efeito do tempo de insolação póscolheita sobre a qualidade do melão amarelo. Horticultura Brasileira, Brasília, v.16, n.1, p.80-81, 1998.

NAGATA, T. A novel melon flexivirus transmitted by whitefly. Archives of Virology, Austria, v.150, p.379-387, 2005.

PROTRADE. Melons - Export manual: tropical fruits and vegetables. Eschborn: GTZ, 1995. 36p.

SALES JÚNIOR, R. et al. Qualidade do melão exportado pelo porto de Natal. Horticultura Brasileira, Brasília, v.22, n.1, p.98-100, 2004

SILVA, G.F. et al. Amarelão do meloeiro: ensaios preliminares de transmissão por mosca branca. Caatinga, Mossoró, v.15, n. $1 / 2$, p.29-33, 2002

SOARES, S.P.F. Qualidade do melão (Cucumis melo L.) exportado pelo porto de Natal-RN. 2001. 55f. Monografia (Graduação em Agronomia) - Escola Superior de Agricultura de Mossoró.

SOUZA, M. da C. et al. Tecnologia pós-colheita e produção de melão no Estado do Rio Grande do Norte. Horticultura Brasileira, Brasília, v.12, n.2, p.188-190, 1994.

VALLESPIR, A.N. Post-recolección de hortalizas. Compendio de Horticultura, v.III, 301p, 1999. 